\title{
The trend towards nephron-sparing procedures for renal masses: Surprisingly slow or reassuringly rapid?
}

\author{
Christopher B. Allard, MD; Luis H. Braga, MD, FRCSC
}

McMaster Institute of Urology, McMaster University, Hamilton, ON

See related article on page e386.

Cite as: Can Urol Assoc J 2013;7(5-6):e450-4. http://dx.doi.org/10.5489/cuaj.1350 Published online June 12, 2013.

W e read with interest the paper by Hammett and colleagues in this issue of CUAJ. ${ }^{1}$ The authors investigated trends in the proportion of nephronsparing surgeries (partial nephrectomy and ablative procedures) versus radical nephrectomy in the management of renal masses in Virginia and Kentucky by searching ICD-9 codes from 2004 to 2009. The authors used the Virginia Department of Health Patient Level Database and the Kentucky Hospital Association database to retrieve patient information.

The increased popularity of research based on administrative datasets of this kind can be attributed to their availability, large size, low cost and perceived real world applicability. ${ }^{2}$ Nevertheless, the limitations of these datasets should not be overlooked. They were not designed for clinical research and, as a result, they lack structured data collection processes and have limited links to pertinent clinical information.

The validity of a database (i.e., whether the available information accurately reflects the true characteristics of a study population) is the first issue to consider when appraising studies of this kind. Uncertainty arises due to difficulty determining whether a condition is truly absent or merely unrepresented due to coding imprecision. The authors attempted to minimize inaccuracies by excluding ICD-9 codes pertaining to upper tract urothelial tumours. However, the accuracy of ICD-9 codes remains questionable and might have been clarified by cross-referencing with procedure codes or other databases.

During the 6-year study period, the use of nephrectomy decreased from $74.3 \%$ to $67.3 \%$ of all surgeries performed for renal malignancies in Virginia and from $80.5 \%$ to $66 \%$ in Kentucky. The vast majority of nephron-sparing surgeries were partial nephrectomies.
The lack of statistical analysis to demonstrate that the reported trends are not random fluctuations is a limitation. If we are to conclude, by comparing data from 2004 to 2009 , that there is a trend towards decreased nephrectomy use in both states, then we would also have to conclude that there has been a trend towards increased nephrectomy use in Virginia from 2005 to 2009. The lack of a priori justification for the selected study period may threaten the validity of the results.

Reasons for the apparent increased use of nephron-sparing surgeries are likely multifactorial. Recent studies support the use of partial nephrectomy over radical nephrectomy when feasible, suggesting comparable oncologic outcomes with decreased risk of chronic kidney disease and other medical comorbidities. ${ }^{3-5}$ Additionally, while the authors did not evaluate the use of laparoscopic or robotic approaches, the increased adoption of robotic technology has been associated with an increased use of partial nephrectomy. ${ }^{6}$

While the apparently slow adoption of nephron-sparing surgeries highlighted in this study may seem disheartening, the findings should be interpreted with caution. Since data on tumour characteristics (e.g., stage, location, etc.) were not available, the results included renal masses which would not have been amenable to nephron-sparing surgeries. Additionally, the increased emphasis on nephron-sparing surgeries has coincided with an increased interest in active surveillance for small renal masses, likely excluding a subset of tumours which would have been particularly amenable to nephron-sparing surgeries.

As one might expect, the trend towards increased nephronsparing surgeries observed by Hammet and colleagues is most pronounced in academic centres. Taking into consideration the study's inclusion of higher stage renal masses, the inherent limitations of administrative databases, and the exclusion of patients undergoing active surveillance (the ultimate nephron-sparing approach), the fact that nephron-sparing procedures comprised $43 \%$ of procedures in academic centres in 2009 is perhaps quite reassuring. 
Competing interests: None declared.

\section{References}

1. Hammett J, Ko J, Byrd N, et al. Patterns of care for renal surgery: underutilization of nephron-sparing procedures. Can Urol Assoc J 2013;7:e386-92. http://dx.doi.org/10.5489/cuaj.12066. Epub 2012 Nov 14.

2. Schneeweiss $S$, Avorn J. A review of uses of health care utilization databases for epidemiologic research on therapeutics. J Clin Epidemiol 2005;58:323. http://dx.doi.org/10.1016/i.jlinepi.2004.10.012

3. Van Poppel H, Da Pozzo L, Albrecht W, et al. A prospective, randomised EORTC intergroup phase 3 study comparing the oncologic outcome of elective nephron-sparing surgery and radical nephrectomy for lowstage renal cell cacinoma. Eur Urol 2011:59:543-52. http://dx.doi.org/10.1016/j.eururo.2010.12.013
4. Kim SP, Thompson RH, Boorijan SA, et al. Comparative effectiveness for survival and renal function of partial and radical nephrectomy for localized renal tumors: a systematic review and meta-analysis. J Urol 2012;188:51-7. http://dx.doi.org/10.1016/i.juro.2012.03.006

5. Huang WC, Elkin EB, Levey AS, et al. Partial nephrectomy versus radical nephrectomy in patients with small renal tumors - is there a difference in mortality and cardiovascular outcomes? J Urol 2009;181:5562. http://dx.doi.org/10.1016/i.juro.2008.09.017

6. Patel HD, Mullins JK, Pierorazio PM, et al. Trends in renal surgery: robotic technology is associated with increased use of partial nephrectomy. J Urol 2013;189:1229-35. http://dx.doi.org/10.1016/i.juro.2012.10.024

Correspondence: Dr. Christopher B. Allard, Institute of Urology, 3rd Floor room G344, 50 Charlton Ave. East, Hamilton, 0N L8N 4A6; ceebuler@hotmail.com 